\title{
Regulative, Normative, and Cognitive Elements of Organizations: Implications for Managing Change
}

\author{
Jennifer Palthe ${ }^{1, *}$ \\ ${ }^{1}$ Department of Management, Western Michigan University, Kalamazoo, USA \\ *Correspondence: Department of Management, Haworth College of Business, Western Michigan University, 1903 \\ W Michigan Ave, Kalamazoo, MI 49008- 5429, USA. Tel: 1-269-387-5798. E-mail: jennifer.palthe@wmich.edu
}

Received: April 21, 2014

Accepted: May 4, 2014 Online Published: May 27, 2014

doi:10.5430/mos.v1n2p59

URL: http://dx.doi.org/10.5430/mos.v1n2p59

\begin{abstract}
Drawing support from current and seminal work on institutional theory, this paper explores the role of three elements involved in the management of change - regulative, normative, and cognitive. While organizational change traditionally deals with challenges associated with changing technologies, structures, and employee abilities, effective change also depends on the values and behavioral reasoning that originate in the institutional context whether people have to change, ought to change, or want to change. A conceptual model reflecting the interplay of these systems on organizational change is presented, and implications for change management research and practice are extended.
\end{abstract}

Keywords: institutional theory; change resistance; change capacity; sustained change

\section{Introduction}

The growing complexity of regulative, procedural, and cultural changes affecting contemporary organizations has precipitated the increasing centrality of change management research and practice in recent decades. Despite the mounting importance of this subject in numerous academic fields, and the proliferation of books on the phenomenon, the literature on organizational change has been described as deficient in sound theoretical frameworks (Ford, Ford, \& D’Amelio, 2008, Ford \& Ford 1994; Worren, Ruddle, \& Moore, 1999). Traditionally, organizational change has been conceptualized as essentially a problem of changing technologies, structures, and the abilities of employees (Ogbor 1990). Although this is desirable, effective change also depends on the values, norms, and obligations of the change agents and change recipients in their response to change. Some change recipients may change because it is regulated company policy (have to change), others may simply change because it becomes the expected norm (ought to change), and other recipients may personally value the change and therefore embrace it (want to change). It is these values, norms and obligations that originate in the institutional context - regulative, normative, and cognitive that constrain and support the operation of organizations (Scott, 1995).

Institutional theory has generated a significant volume of work over the past three decades (Aten \& Howard-Grenville, 2012; Aldrich, 1994; Dacin, 1997; Lawrence, Winn, \& Jennings, 2001; Peng \& Heath, 1996; Sherer \& Lee 2002; Suchman, 1995; Zilber, 2012), yet there is still a paucity of studies showing how institutional systems affect organizational change. Greenwood, Suddaby \& Hinnings' (2002) study of professional associations and the transformation of institutional processes is a rare example. Of the other studies that do exist, most have emphasized the importance of regulative and cognitive pressures in driving institutional change (e.g. Delbridge \& Edwards, 2013; Heracleous \& Barrett, 2001; Huy, 2001). Significant attention to the interplay between regulative, normative, and cognitive pressures to affect organizational change has not been as forthcoming.

This paper examines the current and seminal work on institutional theory and its relationship to organizational change. The interplay between regulative, normative, and cognitive institutional elements and their impact on the institutional context and organizational change is explored. A conceptual framework of organizational change is presented and implications for research and practice are extended. 


\section{Institutional Theory and Change}

Institutional theory is not typically perceived as a theory of organizational change. Rather, it has traditionally been used to explain stability and similarity in a given population or field of organizations. Consistent with Greenwood and Hinings (1996), however, this paper supports the view that institutional theory is a useful framework to provide an explanation for change in organizations as it signals the contextual dynamics that precipitate the need for organizational change.

The central thesis of institutional approaches is that many structures, programs, and practices in organizations achieve legitimacy through the social construction of reality. Meyer and Rowan (1977) stated that institutionalism involves the processes by which social processes and obligations come to take on rule-like status in social thought and action. Scott (1981) asserted that institutionalism is viewed as the social process by which individuals come to accept shared definitions of reality - the process by which actions are repeated and given similar meaning by oneself and others. Sometimes cultural influences such as expectations, norms, and values ensure their repetition, and other times, social influences such as desiring to look like or benchmark another institution alter it (Hatch, 1997; Hatch, 2012). Essentially, institutions are dynamic and display processes of change. They are "created, maintained, changed, and decline" (Hatch \& Zilber, 2012, p. 95).

From the rational perspective, institutions consist of distinctive values that are explicitly expressed by all organizational members. Universities, for example, are guided by educational values, and governments are guided by political values. These institutional effects can be observed both within organizations and their environments, and operate to produce common understandings about what is appropriate organizational behavior.

\section{Conceptual Model of Organizational Change}

A framework for understanding organizational change advanced in this paper is reflected in Figure 1 below. The purpose of this framework is not to develop a comprehensive linear causal model. Rather, the Figure aims to exemplify several conceptually important relationships among institutional elements and variables discussed in this paper. Figure 1 illustrates the connections between the institutional elements and organizational change via intra-organizational dissatisfaction with the current modes of operation. It suggests that the impact of this dissatisfaction with the existing methods and systems on change is restrained by the organization's capacity for change, and the level of resistance to the change.

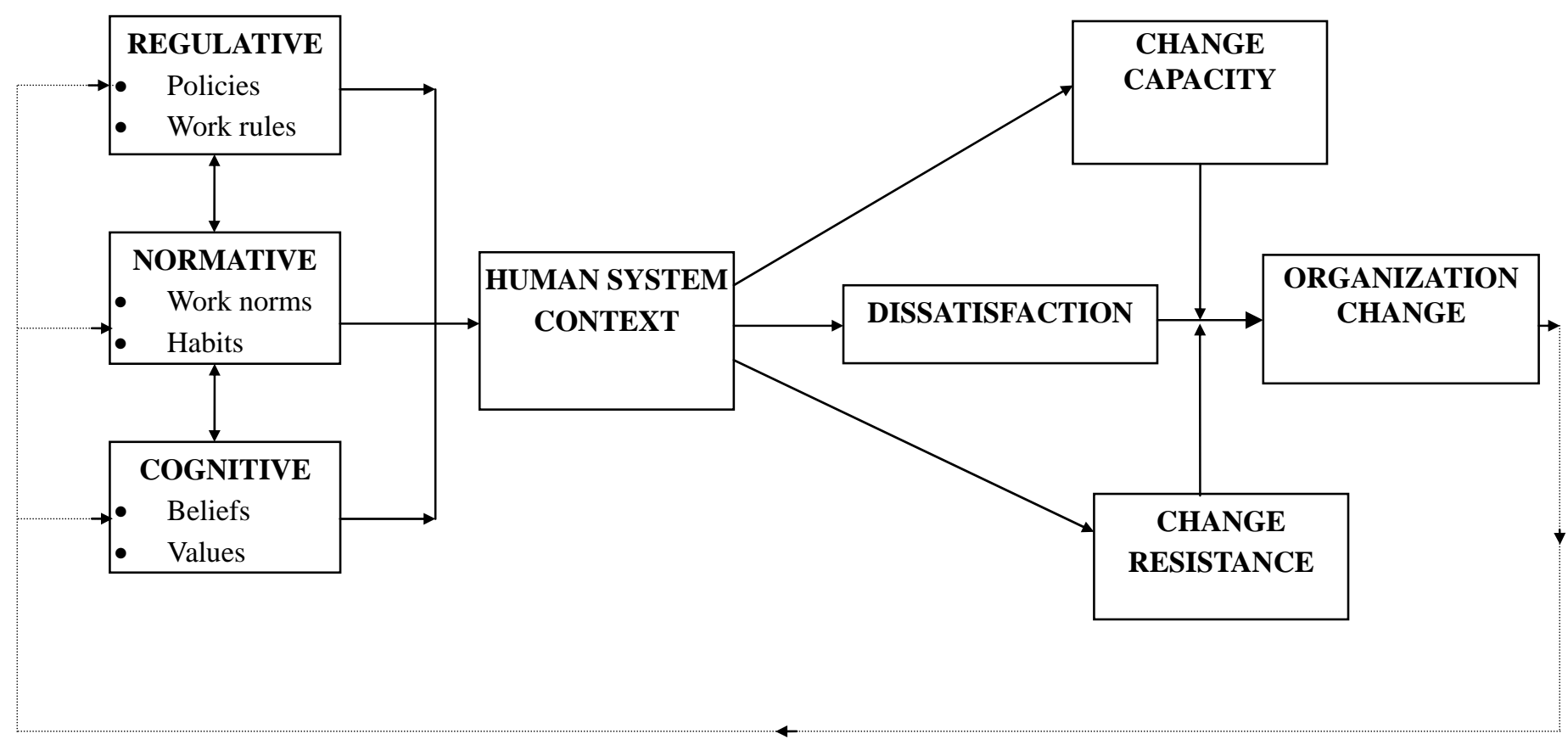

Figure 1. Conceptual Model of the Influence of Regulative, Normative and Cognitive Elements on Organizational Change 


\section{Regulative, Normative and Cognitive Elements of Institutions and Their Relationship to Organizational Change}

Regulative, normative, and cognitive social systems have all been identified by theorists as central elements of institutions (Scott, 1995). Figure 1 suggests that these elements act together in mutually reinforcing ways to contribute to the institutional context. Table 1 exemplifies some of the key dimensions along which these elements differ.

Table 1. Regulative, Normative, and Cognitive Elements Associated with Organizational Change

\begin{tabular}{|c|c|c|c|}
\hline & Regulative & Normative & Cognitive \\
\hline Legitimacy & Legal systems & Moral and ethical systems & Cultural systems \\
\hline Central Rudiments & Policies and rules & $\begin{array}{l}\text { Work roles, habits and } \\
\text { norms }\end{array}$ & Values, beliefs and assumptions \\
\hline System Change Drivers & Legal obligation & Moral obligation & Change values are internalized \\
\hline $\begin{array}{l}\text { System Change } \\
\text { Sustainers }\end{array}$ & Fear and coercion & Duty and responsibility & $\begin{array}{l}\text { Social identity and personal } \\
\text { desire }\end{array}$ \\
\hline Behavioral Reasoning & Have to & Ought to & Want to \\
\hline
\end{tabular}

As portrayed in Table 1 above, institutional theorists tend to differ in the primacy they ascribe to the various elements of institutions. Theorists emphasizing the regulative view of institutions (e.g. Barnett \& Carroll, 1993) are likely to view organizational change as fundamentally a product of market forces and regulative organizational elements such as new policies driven through coercive means. Normative theorists (e.g. Selznick, 1948) emphasize the role of social obligation and are likely to focus on informal structures rather than formal structures in organizational change. They are also likely to emphasize the immediate environment of organizations rather than the more general cultural rules of the society at large in driving such organizational change. Cognitive theorists, or those examining changes in the cognitive aspects of organizations (e.g. Powell \& DiMaggio, 1991), are likely to focus on changes in conceptual beliefs, mental models, and interpretations of shared meanings when organizations go through significant change. This perspective also stresses the importance of achieving change that is internalized by organizational members and culturally supported.

Many scholars accept the regulative aspects of institutions, recognizing that they constrain and regularize organizational behavior (Scott, 1981; Meyer \& Scott, 1983). However, some would view the role of regulative processes in a more explicit and formal sense. Economists, for example, may view regulative processes like rule systems and enforcement mechanisms as the key drivers of institutional change. On the other hand, those who view institutions as primarily normative in nature, such as sociologists, may view change as a product of social obligation rather than mere expedience. These normative systems include values pertaining to preferred behavior and norms specifying how things should be done (Scott, 1995). In essence, they define legitimate means to pursue valued ends. While these normative expectations impose constraints on behavior, they also serve to empower and enable change.

Each of these elements (regulative, normative, and cognitive) provides a basis for legitimacy - a condition reflecting congruence with rules or laws, normative support, or cultural alignment (Scott, 1995). However, as reflected in Table 1 , the regulative element emphasizes conformity to legal systems as the bases of legitimacy. The normative element stresses the moral bases for assessing legitimacy, and the cognitive element emphasizes cultural legitimacy that comes from adopting a shared mindset.

By relating these paradigms to the concept of organizational change, the factors that potentially play a role in resisting or igniting change are illuminated. From the regulative perspective, legal obligation may be the essential driver of change, with coercion and fear acting as key factors perpetuating that change. Here, organizational members change because they have to and not necessarily because they want to. From the normative perspective, a sense of duty and moral obligation form the essential ingredients of what drives change. Organizational members feel they ought to change out of a sense of duty and obligation even if they do not identify with the rationale for the change or believe that it will succeed. From the cognitive perspective, for genuine organizational change to be generated and sustained, the premises of change would need to be internalized and valued by organizational members. Here, members choose to adopt and support a change because they believe in it and personally want to support it, even if it is not enforced through an organizational policy (regulative) or workplace norm (normative). 


\section{Market and Institutional Contexts and Their Relationship to Change}

Institutional theorists insist that organizational behavior is a product of values and beliefs that originate in the institutional context (Meyer \& Rowan, 1977; Zucker, 1983). Survival, they assert, is dependent on an organization's ability to accommodate institutional expectations, even when these expectations have little or nothing to do with the technical aspects of performance accomplishment (Scott, 1981). Institutional theory, therefore, illustrates how organizational behaviors are not necessarily just responses to market pressures but also products of the institutional context.

Morrison (1995) and Scott (1995) assert that social actions are not context free, but are constrained and shaped by the setting in which they occur. The difference between institutionalized and non-institutionalized contexts often appears on the surface to be a matter of rationality. From this perspective, the economic and technical success in the market context is viewed as a product of rational decision making (Hatch, 1997). Rationality alone, however, does not distinguish institutionalized from non-institutionalized environments because rationalities can become contextualized (Scott, 1995).

Conformity to pressures from the institutional context gives rise to social support and ensures survival of an organization, not because it elicits greater profits or better products, but because it goes along with accepted conventions (Hatch, 1997). Making decisions, for example, that only superficially conform to the norms of rationality can be an effective way to legitimize choices. Meyer and Rowan (1977), for example, assert that these rationalized arguments manifest themselves in the form of myths that cannot objectively be tested, but are classified as rational in that everyone knows them to be true. Rationalized myths form part of the institutional context in which organizations operate and to which they adapt in order to maintain their social legitimacy (Hatch, 1997). This notion of social legitimacy constitutes one of institutional theories greatest contributions. Organizations not only require labor, capital, knowledge, and materials, but also depend on the acceptance of the society in which they operate. This becomes of critical importance when organizations are undergoing significant change and becoming increasingly global. These changes, fueled by globalization, create a situation where market contexts and cross-cultural contexts begin to influence the institutional context in new and diverse ways. Hence, critical to an organization's survival and success is its ability to adapt not merely to its market environment, but its institutional environment as well.

Every organization is a subsystem of a wider social system. This wider social system serves as the source of meaning, legitimacy, or higher level support that makes the implementation of the organization's goals possible. Organizations are not simply the product of increasing technical sophistication but are the result of the increasing rationalization of cultural rules (Meyer \& Rowan, 1977). Figure 1 seeks to capture these contexts and the role they play in influencing intra-organizational dynamics and organizational change in particular. The Figure also illustrates how the regulative, normative, and cognitive elements form the fundamental building blocks of the institutional context. Moreover, these contexts differ in terms of the strength that the mimetic, normative, and coercive pressures pertaining to the elements exert (i.e. the extent to which change may occur due to deinstitutionalization). Because of these forces, substantial or radical change is often difficult not just because of the challenge of gaining support, but also because of the normative embeddedness of an organization within its institutional context (Baum \& Oliver, 1992). The greater the degree of embeddedness the more difficult is the achievement of significant change. On this note, drawing from the work of March and Simon (1958), Meyer and Rowan (1977), and Weick (1995), the greater the extent to which organizations are tightly coupled with their environments, the greater the potential resistance to change. Tight coupling refers to the existence of mechanisms for dissemination and the monitoring of compliance in combination with a consistent set of expectations (Greenwood \& Hinings, 1996). However, this also suggests that if the institutional prescriptions change dramatically and the organization is tightly coupled with it, the result would be dramatic or revolutionary organizational change, not convergent and evolutionary change. Powell and DiMaggio (1991) assert that the institutional context provides "templates for organizing" (p.27). Conceptualizing organizational arrangements in terms of these templates provides a powerful definition of convergent and radical change in organizations. Convergent change occurs within the boundaries of existing templates. Radical change, on the other hand, occurs when organizations move from one template to another, involving a redefinition of meanings and interpretive schemes. This implies that if researchers and change specialists are to understand why it is difficult for organizations to change, they must first explore that which holds members of the organization to their old sets of actions, and what factors promote dissipation. 


\section{Dissatisfaction with the Current Status}

Some would argue that organizations are arenas in which coalitions with different interests and capacities for influence vie for control (Greenwood \& Hinings, 1996). A potential driver of change, then, is the extent to which groups are dissatisfied with the current organizational state and existing structures, policies, and practices. High levels of dissipation and dissatisfaction become a pressure for change. Dissipation is a gradual deterioration in the acceptance and use of a particular institutionalized practice (Oliver, 1992). Deinstitutionalization stemming from the process of dissipation may include elements such as inadequate socialization, the intrusion of personal interests, and changed circumstances that render current beliefs or practices ineffectual (Scott, 1995). Dissatisfaction therefore also becomes a pressure for change, as reflected in Figure 1.

\section{Change Capacity}

Figure 1 suggests that an organization's capacity to change is related to the degree to which change may occur. Essentially, the Figure serves to illustrate that an organization's capacity to change influences the extent to which change will occur as driven by high levels of dissatisfaction and dissipation. Organizations less embedded in their institutional contexts are likely to be less committed to prevailing practices and more likely to change and develop new ones. When the legitimacy of an institutionalized practice gradually erodes (Oliver, 1992), the capacity for gradual reshaping of consciousness within individuals and groups is likely to occur. Change capacity is also determined by the organization's ability to adapt, learn, and apply new innovations through human, strategic, technological, and structural competencies and methods. This change capacity, as suggested by Figure 1, is likely to inhibit or enhance the relationship between the level of dissatisfaction in the organization and the degree of organizational change.

\section{Change Resistance}

Figure 1 illuminates how resistance to change moderates the extent to which dissatisfaction with the status quo induces change. The greater the change resistance, the less will be the effect that the level of dissatisfaction will have on organizational change. Essentially then, change capacity and change resistance determine the intensity or degree of change that is stimulated by the dissatisfaction of organizational members. Change will only be significant if it is accepted and supported by the change recipients. For example, employees not adhering to new procedures may undermine regulative changes. In addition, employees who do not feel the changes are ethical may undermine normative changes. Finally, if the changes are inconsistent with the change recipient's conceptual beliefs, the necessary cognitive change is likely to be resisted. As Figure 1 suggests, change capacity and change acceptance are necessary, but not sufficient conditions for organizational change. They serve to either constrain or enable it.

\section{Implications for Practice}

Institutional theory suggests that social legitimacy, whether regulative (have to), normative (ought to) or cognitive (want to), should be considered as an input to organizational change along with raw materials and other resources upon which the process of change depends. Organizations develop along with changes occurring in their context, and change management calls for an understanding of this. No organization is self-sufficient; they all depend for survival on the types of relations they establish with the larger systems (local and global) of which they are a part. The institutional perspective emphasizes the fact that not everything that happens is necessarily intended and that not all outcomes are the result of conscious and rational decision processes. Many processes may in fact be a result of social construction processes whereby external entities influence the creation and implementation of practices that come to attain a level of legitimacy. Moreover, as Zilber (2008) argues, institutionalization is an ongoing process rather than an end point. Consequently, practitioners need to ask themselves the question: how often do practices in organizations merely continue to exist, not because of their effectiveness, but due to organizational inertia? Change management specialists need to be particularly aware of this when they try and understand why, for example, their new change initiatives fail to gain support, or why some change interventions do not succeed in sustaining themselves over time.

Since institutional structures are highly resistant to change, for change to occur, the taken-for-granted quality must be brought into question. While changes in institutional structures can occur quite rapidly in the form of revolutionary or episodic change, these changes usually involve the reallocation of individuals among existing institutional 
definitions, rather than the creation of new definitions. Such transformations can alter behavior substantially, and redistribute rights and resources, as in the case of corporate restructurings or global mergers. So, although transformations of institutional structure (regulative elements) may be brought about swiftly, cognitive restructuring needs to take place incrementally and with substantial initial integration of the prior and emergent institutional structures. Practitioners and change consultants need to recognize the nature and content of the change associated with each element of the institutional context in their pursuit of effective change management.

Regulative elements of change (i.e., changes in policies and procedures) are likely to be associated with rapid, episodic change, while normative elements (i.e., changes in workplace habits and norms), and cognitive elements (i.e., changes in beliefs about work roles) are likely to be associated with long-term, continuous change. Moreover, they need to appreciate that regulative, normative, and cognitive elements are all important components of the institutional context and although they differ in terms of their emphasis, all three can and do play a role in the process of organizational change.

Organizational change is challenging not solely because of the difficulties of igniting internal support and poor organizational learning. These challenges also stem from the normative embeddedness of an organization within its institutional context. The greater the embeddedness, the greater the resistance to change and the more difficult is the attainment and sustaining of significant organizational change. Furthermore, as Pettigrew, Woodman, and Cameron (2001) argue, explanations for organizational change cannot simply be pared down to the relationships between independent and dependent variables but should be viewed as interactions between context and action. The role of intra-organizational dynamics in accepting or rejecting the institutional context and its associated practices cannot be underestimated. Likewise, as Zilber (2002) suggests, scholars should take into account the processual and dynamic nature of an organization's institutional elements and the interplay between institutional actions, meanings, and actors. Practitioners and change management specialists need to take heed of these assertions, particularly those implementing large-scale reengineering initiatives that by definition attempt to induce gamma level organizational change.

\section{Conclusion and Directions for Future Research}

The framework presented in this paper and elaborated upon in Table 1 seeks to offer a way of organizing past conceptualizations of institutions while raising additional questions to guide future research. Scott's (1995) argument that institutional arrangements are likely to combine regulative, normative, and cognitive processes together in varying amounts, and Figure 1's illumination of this notion, needs to be tested empirically. For example, do regulative structures attempt to move toward the creation of a normative base? Furthermore, as Scott (1995) suggests, do normative and regulative structures operate within cognitive frames? These are questions that remain essentially unanswered, empirically.

Organizations that incorporate institutionalized myths are more legitimate, successful, and likely to survive according to Meyer and Scott (1983). With this in mind, research should compare similar organizations in different contexts. For example, organizational success could be predicted in environments in which organizational change practices are widely institutionalized. Experimentally researchers could, for example, study the degree of environmental institutionalization and the degree to which organizations incorporate environmental institutions, domestically and internationally. Are certain organizational change tendencies more prevalent in certain societies where they are widely institutionalized? In highly institutionalized contexts are organizational change efforts devoted more to value conformity? In these situations, do managers devote more time to managing change with respect to their public image than internal efficiencies?

Scott (1995) argues that we need to broaden current research agendas. He asserts that social science remains overly parochial and we are too prone to select our study population out of convenience rather than theoretical promise. In particular, we are too prone to study systems close to us in time and place. We do this in spite of the fact that these are the very systems that are most difficult to see with fresh lenses. These systems, he argues, "co-opt and corrupt our vision" because we are likely to share many of our subjects' beliefs and assumptions. In order to address these deficiencies we need "frame-breaking experiences" that only come from "examining and comprehending organizations operating in other places and other times" (Scott, 1991, p. 151). Consistent with this argument, Pettigrew, Woodman, and Cameron (2001) assert that there is a need to reconcile the social and organizational sciences, to transcend current scholarly beliefs and routines, and to supplement disciplinary knowledge on organizational change rather than supplant it. In response to this call, researchers need to continue striving to understand variations in organizational change dynamics among societies, and within societies across time. Also, 
institutional researchers could explore how micro-level organizational culture dynamics influence, and are influenced by, the macro-level institutional context (Zilber, 2012). Similarly, scholars could investigate ways that organizational level efforts add up to changes at the inter-organizational level (Hatch \& Zilber, 2012). By emphasizing how the regulative, normative, and cognitive elements in the institutional context play a role in igniting, precipitating, and sustaining change, this paper has sought to inspire scholars to further develop and execute comparative and experimental studies examining the effects of these institutional dynamics on organizational change.

\section{References}

Aldrich, H. E., \& Fiol, C. M. (1994). Fools rush in? The institutional context of industry creation. Academy of Management Review, 19, 645-670.

Aten, K., \& Howard-Grenville, J. (2012). Encouraging trade at the boundary of organizational culture and institutional theory. Journal of Management Inquiry, 21(1), 114-117. http://dx.doi.org/10.1177/1056492611419803

Barnett, W. P., \& Carroll, G. R. (1993). How institutional constraints affected the organization of early U.S. telephony. Journal of Law, Economics, and Organization, 9, 98-126.

Baum, J. A., \& Oliver, C. (1992). Institutional embeddedness and the dynamics of organizational populations. American Sociological Review, 57, 540-559. http://dx.doi.org/10.2307/2096100

Dacin, M. T. (1997). Isomorphism in context: The power and prescription of institutional norms. Academy of Management Journal, 40(1), 46-81. http://dx.doi.org/10.2307/257020

Delbridge, R., \& Edwards, T. (2013). Inhabiting institutions: Critical realist refinements to understanding institutional complexity and change. Organization Studies, 34(7), 927-947. http://dx.doi.org/10.1177/0170840613483805

Ford, J., D., \& Ford, L. W. (1994). The logics of identity, contradiction, and attraction in change. Academy of Management Review, 33(2), 362-377. http://dx.doi.org/10.5465/AMR.2008.31193235

Ford, J., D., Ford, L., \& D'Amelio, A. (2008). Resistance to change: The rest of the story. Academy of Management Review, 19(4), 756-785.

Greenwood, R., \& Hinings, C. R. (1996). Understanding radical organizational change: Bringing together the old and the new institutionalism. Academy of Management Review, 21(4), 1022-1054.

Greenwood, R., Suddaby, R., \& Hinings, C. R. (2002). Theorizing change: The role of professional associations in the transformation of institutionalized fields. Academy of Management Journal, 45(1), 58-80. http://dx.doi.org/10.2307/3069285

Hatch, M. J. (1997). The environment of the organization. Organizational Theory: Modern Symbolic and Postmodern Perspectives. New York, Oxford University Press.

Hatch, M. J. (2012). Bringing culture back from institutional Siberia. Journal of Management Inquiry, 21(1), 84-87. http://dx.doi.org/10.1177/1056492611419791

Hatch, M. J., \& Zilber, T. (2012). Conversation at the border between organization culture theory and institutional theory. Journal of Management Inquiry, 21(1), 94-97. http://dx.doi.org/10.1177/1056492611419793

Heracleous, L., \& Barrett, M. (2001). Organizational change as discourse: Communicative actions and deep structures in the context of information technology implementation. Academy of Management Journal, 44(4), 697-713. http://dx.doi.org/10.2307/3069414

Huy, Q. N. (2001). Time, temporal capability, and planned change. Academy of_Management Review, 26(4), 601-623. http://dx.doi.org/10.2307/3560244

Kraatz, M. S., \& Moore, J. H. (2002). Executive migration and institutional change. Academy of Management Journal, 45(1), 120-143. http://dx.doi.org/10.2307/3069288

Lawrence, T. B., Winn, M. I., \& Jennings, P. D. (2001). The temporal dynamics of institutionalization. Academy of Management Review, 26(4), 624-644.

March, J. G., \& Simon, H. A. (1958). Organizations. New York: Wiley.

Meyer, J. W., \& Rowan, B. (1977). Institutionalized organizations: formal structure as myth and ceremony. 
American Journal of Sociology, 83, 340-363. http://dx.doi.org/10.1086/226550

Meyer, J. W., \& Scott, W. R. (1983). Organizational Environments. Beverly Hills: SAGE.

Morgan, G. (1986). Images of Organization. Newbury Park, CA: SAGE.

Ogbor, J. (1990). Organizational Change within a Cultural Context. Sweden: Lund University Press.

Oliver, C. (1992). The antecedents of deinstitutionalization. Organizational Studies, 13, 563-588. http://dx.doi.org/10.1177/017084069201300403

Peng, M. W., \& Heath, P. S. (1996). The growth of the firm in planned economies in transition: Institutions, organizations, and strategic choice. Academy of Management Review, 21(2), 492-528.

Pettigrew, A. M., Woodman, R. W., \& Cameron, K. S. (2001). Studying organizational change and development: challenges for future research. Academy of Management Journal, 44(4), 697-713. http://dx.doi.org/10.2307/3069411

Powell, W., \& DiMaggio, P. (1991). The New Institutionalism in Organizational Analysis. Chicago, IL: University of Chicago Press.

Scott, W. R. (1981). Organizations: Rational, Natural, and Open Systems. Englewood Cliffs, N.J.: Prentice Hall.

Scott, W. R. (1995). Institutions and Organizations. Thousand Oaks, CA, SAGE.

Selznick, P. (1948). Foundations of the theory of organization. American Sociological Review, 13, 25-35. http://dx.doi.org/10.2307/2086752

Seo, M-G., \& Creed, W. E. D. (2002). Institutional contradictions, praxis, and institutional change: A dialectical perspective. Academy of Management Review, 27(2), 222-247.

Sherer, P. D., \& Lee, K. (2002). Institutional change in large law firms: A resource dependency and institutional perspective. Academy of Management Journal, 45(1), 102-119. http://dx.doi.org/10.2307/3069287

Suchman, M. C. (1995). Managing legitimacy: Strategic and institutional approaches. Academy of Management Review, 20(3), 571-610.

Thompson, J. D. (1967). Organizations in Action. New York: McGraw Hill.

Tichy, N. M. (1983). Managing strategic change: Technical, political, and cultural dynamics. New York: Wiley.

Trice, H. M., \& Beyer, J. M. (1993). The Cultures of Work Organizations. Englewood Cliffs, NJ: Prentice Hall.

Weick, K. E. (1995). Sensemaking in Organizations. Thousand Oaks, CA: SAGE.

Worren, N. A. M., Ruddle, K., \& Moore, K. (1999). From organizational development to change management. Journal of Applied Behavioral Science, 35(3), 273-286. http://dx.doi.org/10.1177/0021886399353002

Zilber, T. B. (2002). Institutionalization as an interplay between actions, meanings and actors: The case of a rape crisis center in Israel. Academy of Management Journal, 45(1), 234-254. http://dx.doi.org/10.2307/3069294

Zilber, T. B. (2008). The work and meanings in institutional processes and thinking. In R. Greenwood, C. Oliver, K. Sahlin, and R. Suddaby (Eds.), The SAGE Handbook of Organizational Institutionalism. London, U.K., SAGE, 151-169. http://dx.doi.org/10.4135/9781849200387.n6

Zilber, T. B. (2012). The relevance of institutional theory for the study of organizational culture. Journal of Management Inquiry, 21(1), 88-93. http://dx.doi.org/10.1177/1056492611419792

Zucker, L. G. (1983). Organizations as institutions. Research in the Sociology of Organizations. S. B. Bacharach. Greenwich, JAI Press. 2, 1-48. 